\title{
HUBUNGAN ANTARA JOB DEMANDS DENGAN WORK ENGAGEMENT: PERANAN FLEXIBLE LEADERSHIP SEBAGAI MODERATOR
}

\author{
Felycia Klaviera Mulyana ${ }^{1}$, P. Tommy.Y. S. Suyasa ${ }^{2}$, dan Raja Oloan \\ Tumanggor $^{3}$ \\ ${ }^{1}$ Program Studi Magister Psikologi, Universitas Tarumanagara, Jakarta \\ Email:felyciak@gmail.com \\ ${ }^{2}$ Fakultas Psikologi, Universitas Tarumanagara, Jakarta \\ Email: tommys@fpsi.untar.ac.id \\ ${ }^{3}$ Fakultas Psikologi, Universitas Tarumanagara, Jakarta \\ Email: rajat@fpsi.untar.ac.id
}

Masuk : 16-04-2020, revisi: 28-04-2020, diterima untuk diterbitkan : 30-04-2020

\begin{abstract}
This study aims to examine the role of flexible leadership as a moderator of job demand variables in predicting work engagement for employees at PT X Kab. Bogor. Job demands are referring to physical, psychological, social, or organizational aspects of a job that require continuous physical or psychological effort or ability and therefore are associated with certain physical and / or psychological costs. Work engagement is a positive, satisfying, motivational state of work-related welfare. Flexible leadership is the ability of a leader to adapt leadership styles and methods in responding to different or changing contextual demands by facilitating group performance. This research was carried out in medical representative participants by filling out an online questionnaire from google form $(N=46)$ with a measurement of job demands from Rothmann with the name JD-R Scale, a measure of work engagement from Bakker using the Utrecht Work Engagement Scale (UWES), and measuring instrument from Kaiser with the name flexible leadership Leadership Versatility Index (LVI). The results of modeling the relationship using SPSS Version 25 show that job demands (work overload) have a strong relationship with work engagement when moderated by high flexible leadership. This finding shows that the function of flexible leadership behavior functions as a moderator at the medical representative at PT. X Regional Bogor.
\end{abstract}

Keywords: job demands, work engagement, and flexible leadership.

\begin{abstract}
ABSTRAK
Penelitian ini bertujuan untuk menguji peranan flexible leadership sebagai moderator dari variabel job demand dalam memprediksi work engagement pada karyawan di PT X Kab, Bogor. Job demands merujuk pada aspek-aspek fisik, psikologis, sosial, atau organisasi dari suatu pekerjaan yang membutuhkan usaha atau kemampuan secara fisik dan atau psikologis yang terus menerus dan oleh karena itu diasosiasikan dengan biaya fisik dan atau psikologis tertentu. Work engagement adalah keadaan yang positif, memuaskan, motivasi-motivasi dari kesejahteraan terkait pekerjaan. Flexible leadership ialah kemampuan seorang pemimpin dalam menyesuaikan gaya kepemimpinan dan metode dalam menanggapi tuntutan kontekstual yang berbeda atau berubah-ubah dengan cara memfasilitasi kinerja kelompok. Penelitian ini dilakukan pada partisipan medical representative dengan cara mengisi kuesioner online dari google form $(\mathrm{N}=46)$ dengan alat ukur job demands dari Rothmann dengan nama JD-R Scale, alat ukur work engagement dari Bakker menggunakan Utrecht Work Engagement Scale (UWES), dan alat ukur flexible leadership dari Kaiser dengan nama Leadership Versatility Index (LVI). Hasil pemodelan hubungan tersebut menggunakan SPSS Versi 25 menunjukkan bahwa job demands (work overload) memiliki hubungan kuat dengan work engagement ketika flexible leadership yang tinggi. Temuan ini menunjukkan bahwa fungsi perilaku flexible leadership berfungsi sebagai moderator pada medical representative di PT. X Kab. Bogor.
\end{abstract}

Kata Kunci: job demands, work engagement, dan flexible leadership.

\section{PENDAHULUAN}

PT. X telah berkembang dari sebuah perusahaan kecil yang didirikan tahun 1969 menjadi salah satu perusahaan farmasi etikal terbesar di Indonesia pada awal abad ke-21. Dan kini, telah menjadi perusahaan terkemuka yang disegani di pasar farmasi domestik. Memberikan pelayanan kesehatan yang lebih baik dengan menerapkan keahlian sebagai landasan yang ditetapkan oleh pendiri perusahaan, yaitu; kepercayaan, dedikasi dan komitmen untuk menyediakan produk 
etikal dan OTC dengan kualitas tertinggi terus dipertahankan. Didukung oleh tim manajemen yang profesional, dan SDM yang memiliki kompetensi, PT. X telah mengembangkan semangat kerjasama saling menghargai, dan inovasi, lebih dari empat dekade. Produk-produk PT. X juga telah dipasarkan/ diekspor ke berbagai negara di kawasan Asia dan Afrika. Sejak dulu, PT. X telah bekerja sama dengan lembaga pemerintah dan Gabungan Perusahaan Farmasi Indonesia untuk mematuhi dan meningkatkan standar industri. Pertumbuhan industri farmasi tidak terlepas dari kontribusi tenaga Medical Representative (MR) untuk mencapai visi dan misi. MR berfungsi untuk melakukan penjualan, kegiatan marketing, atau detailing produk-produk dari industri farmasi kepada dokter. Dengan kata lain MR berfungsi untuk melakukan komunikasi dan meyakinkan dokter agar meresepkan suatu produk (obat) dari suatu industri farmasi. Dalam mempromosikan obat, MR tidak membawa obat yang dipromosikan, melainkan hanya membawa brosur. Berdasarkan brosur, MR menjelaskan kepada dokter atau apoteker mengenai apa saja kegunaan obat yang MR promosikan.

Breevaart dan Bakker (2017) menghipotesakan bahwa perilaku kepemimpinan transformasional setiap hari mendukung keterlibatan kerja karyawan pada hari-hari yang dicirikan oleh job demands dengan tantangan yang tinggi, dan melindungi work engagement pada hari-hari yang dicirikan oleh job demands dengan hambatan tinggi. Namun di lapangan para partisipan mengkondisikan bahwa perilaku kepemimpinan transformasional kurang tepat. Di lapangan lebih kepada pemimpin yang fleksibel. Karena kepemimpinan yang fleksibel sangat penting bagi kemampuan beradaptasi dan kinerja organisasi, mengukur fleksibilitas untuk mengidentifikasi potensi kepemimpinan dan untuk memandu pengembangan manajer. Metode yang paling umum untuk mengukur fleksibilitas manajer melibatkan penilaian rekan kerja untuk item yang menanyakan kecenderungan umum bagi manajer untuk mengubah perilaku sebagai respons terhadap perubahan kondisi situasional. Kaiser (2007) dalam pandangan ini menjelaskan bahwa, kepemimpinan yang fleksibel dikonseptualisasikan sebagai perilaku yang berlawanan namun saling melengkapi dalam hal bagaimana seseorang memimpin dan juga dalam hal apa yang menjadi pemimpin organisasi. Mekanisme penilaian konsepsi kepemimpinan fleksibel ini dijelaskan secara rinci bersamaan dengan demonstrasi kemampuannya untuk memprediksi keefektifan kepemimpinan.

Komitmen kerja ialah adalah keadaan yang positif, memuaskan, motivasi-motivasi dari kesejahteraan terkait pekerjaan (Bakker et al., 2008, hal. 188). Ini didefinisikan dan dioperasionalkan sebagai 'pikiran yang positif, memenuhi pekerjaan yang terkait yang dicirikan oleh kekuatan, dedikasi dan penyerapan' (Schaufeli et al., 2002, p.74). Semangat dicirikan oleh tingkat energi dan ketahanan mental yang tinggi; dedikasi dialami ketika individu antusias, terinspirasi dan ditantang saat melakukan pekerjaan mereka; dan penyerapan ditandai dengan sangat asyik dalam pekerjaan seseorang (Bakker et al., 2008, hal. 188). Penelitian terbaru Dalam komitmen kerja terdapat vigor, MR memberikan fisik, kognitif, dan emosionalnya selama bekerja, dengan bekerja melebihi batas waktu (8jam), bahkan liburan pun harus bekerja karna sanat terlibat dengan dokter langsung. Tetap bertahan dalam pekerjaannya karena banyak tuntutan dalam keluarga dan hidup MR. Dalam dedication, MR termotivasi dalam kehidupannya karena seringnya berkomunikasi dengan dokter, atasan bahkan rekan kerja. Dalam absorption, MR bekerja keras sepanjang hari berada di RS untuk mendatangi banyaknya dokter demi menanyakan kesediaan dokter untuk melunasi target yang akan dicapai dalam penjualan obat. Hal ini juga sejalan dengan berlakunya tuntutan-tuntutan kerja yang didapatkan atau kewajiban MR dalam bekerja. 
Job Demands-Resources ialah dua proses psikologis yang mendasari memainkan peran dalam kesejahteraan individu: sebuah proses yang digerakkan oleh usaha di mana tuntutan pekerjaan yang berlebihan dan kurangnya sumber daya pekerjaan menyebabkan kesusahan, dan proses motivasi-driven di mana sumber daya pekerjaan menyebabkan keterlibatan kerja (Demerouti et al., 2001; Schaufeli \& Bakker, 2004). Meskipun beberapa studi internasional menggunakan model ini untuk menjelaskan pengaruh tuntutan pekerjaan dan sumber daya pada kesejahteraan (misalnya Bakker, Demerouti \& Schaufeli, 2003; Bakker, Demerouti, Taris, Schaufeli \& Schreurs, 2003; Schaufeli \& Bakker, 2004), penelitian diperlukan mengenai tuntutan pekerjaan dan sumber daya seperti yang dialami oleh karyawan di berbagai organisasi di Afrika Selatan. Dalam permasalahan tuntutan kerja yang paling di alami oleh MR ialah work overload, MR memiliki tugas yang terlihat mudah, yaitu bagaimana caranya agar dokter dapat memakai obat yang MR presentasikan kepada dokter. Namun kenyataan yang ada ialah dimana dokter sulit ditemui, acuh, bahkan ada yang diminta menjadi sopir dan membelikan makanan yang terkesan seperti bukan pekerja kantoran. Maka dari sana dapat disimpulkan bahwa MR harus memilik waktu lebih untuk dokter, selain itu pada saat mendekati akhir bulan, MR di push untuk mencapai target yang di berikan oleh perusahaan. Adapula absen pagi yang berbelit dengan kunjungan dokter pagi yang ada di wawancara, yaitu MR diwajibkan mendapat tanda tangan dokter sebanyak sepuluh dokter dalam sehari, namun jarak antara kantor dengan rumah sakit yang di kunjungi kurang lebih menempuh $25 \mathrm{~km} / \mathrm{jam}$, yang artinya tidak mudah dijalani. Belum lagi jika ada MR yang sudah berkeluarga, hari libur atau tanggal merahpun dokter biasanya meminta bantuan atau dana untuk penyelenggaraan liburan dan MR yang harus ikut serta didalamnya.

\section{METODE PENELITIAN}

Dalam penelitian ini menggunakan pendekatan kuantitatif, Penelitian ini termasuk penelitian eksplanatori. Pengambilan sampel untuk dijadikan responden dalam penelitian ini adalah dengan menggunakan seluruh dari populasi yaitu sebanyak 46 pegawai yang bekerja sebagai Medical Representative.

Peneliti menggunakan alat ukur Job Demands dengan menggunakan alat ukur dari S Rothmann et al. (2006), dalam Jurnalnya yang berjudul "A Psychometric Evaluation Of The Job Demandsresources Scale in South Africa" dengan cited by 73. Jumlah butir soal sebanyak 8 butir item menggunakan skala likert dari angka 1 (jarang) hingga angka 4 (sering), dengan Alpha Cronbach 0.946, yang hanya menggunakan Job demands dengan dimensi work overload. Contoh butir soalnya: "Apakah Anda memiliki terlalu banyak pekerjaan yang harus dilakukan?" dan "Apakah Anda bekerja di bawah tekanan waktu?".

Peneliti menggunakan alat ukur komitmen kerja dengan menggunakan alat ukur Work Engagement Scale (UWES), Preliminary Manual [Ver 1.1] Wilmar Schaufeli \& Arnold Bakker (2004) berjumlah 17 butir item dengan Alpha Cronbach 0.941, menggunakan skala likert dari angka 1 (jarang) hingga angka 4 (sering), yang diantaranya terdapat 3 dimensi Vigour, Dedication, dan Absorption, yaitu dengan contoh sebagai berikut: "Saya merasa bersemangat ketika bekerja", "Saya merasa pekerjaan yang saya lakukan memiliki makna dan manfaat yang jelas", dan "Ketika bekerja saya merasa waktu berlalu begitu cepat."

Peneliti menggunakan alat ukur pempimpin fleksibel dengan menggunakan Leadership Versatility Index (LVI), yang di kembangkan oleh Robert B. Kaiser dan Kaplan (2012). LVI berisi empat skala utama masing-masing terdiri dari 12 item; Skala yang Kuat dan Aktif mewakili cara bagaimana interpersonal orang tersebut, dan pada skala Strategis dan Operasional 
mewakili apa organisasi yang tepat untuk orang tersebut (Kaiser et al., 2008). Terdapat 24 butir item dengan Alpha Cronbach 0.964, menggunakan skala likert dari angka 1 (jarang) hingga angka 4 (sering), yang diantaranya terdapat 2 dimensi dan 4 sub-dimensi, yaitu dengan contoh sebagai berikut: "Atasan mengambil alih seluruh tanggung jawab yang seharusnya dikerjakan oleh bawahan", dan "Atasan memberdayakan bawahan yang sudah mahir dalam bekerja."
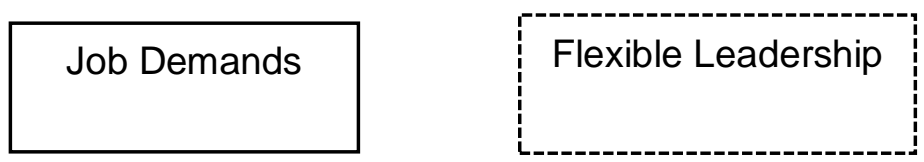

Work Engagement

Berdasarkan hal tersebut di atas, maka dapat diketahui sebagai berikut:

$\mathrm{H}_{1}$ : Work engagement berhubungan dengan Job demands

$\mathrm{H}_{2:}$ Work engagement dengan Job demands dapat dimederatori oleh flexible leadership

Variabel-variabel yang dioperasionalisasikan adalah semua variabel yang terkandung dalam hipotesis. Work Engagement (X) merupakan variabel sebagai keadaan positif, pemenuhan, pandangan terhadap kondisi kerja yang dikarakteristikkan dengan adanya vigor, dedication dan absorption (Schaufeli, Salanova, Gonzalez-Roma, \& Bakker, 2008). Job demands (Y) adalah hal fisik, atau aspek organisasional dalam pekerjaan yang membutuhkan fisik terus menerus maupun usaha psikologis yang dengan secara langsung, hal ini akan berasosiasi dengan pengeluaran psikologis (Demerouti et al., 2001). Flexible leadership (Z) mengukur kemampuan seorang pemimpin dalam menyesuaikan gaya kepemimpinan dan metode dalam menanggapi tuntutan kontekstual yang berbeda atau berubah-ubah dengan cara memfasilitasi kinerja kelompok (Kaiser \& Overfield, 2010). Dalam variabel operasional dalam penelitian ini akan diringkas pada tabel dibawah ini seperti berikut:

Tabel 1. Variabel Operasional Penelitian

\begin{tabular}{|c|c|c|}
\hline Variabel & Dimensi & Indikator \\
\hline & & Semangat dalam kerja \\
\hline & & . Energik dalam bekerja \\
\hline & Vigor & Keinginan mengerjakan tugas \\
\hline & & Kesanggupan bekerja lama \\
\hline \multirow{6}{*}{$\begin{array}{l}\text { Work } \\
\text { Engagement } \\
\text { (Bakker, et } \\
\text { al. 2008) }\end{array}$} & & Mampu mengatasi pekerjaan dibawah tekanan \\
\hline & Absorption & $\begin{array}{l}\text { Bekerja menyenangkan } \\
\text { Tekun mengerjakan tugas } \\
\text { Menikmati pekerjaan }\end{array}$ \\
\hline & & Pekerjaan memiliki makna dan manfaat \\
\hline & & Antusias dalam bekerja \\
\hline & Dedication & $\begin{array}{l}\text { Pekerjaan memberi inspirasi } \\
\text {. Bangga dengan pekerjaan }\end{array}$ \\
\hline & & Pekerjaan itu menantang \\
\hline $\begin{array}{l}\text { Job } \\
\text { Demands } \\
\text { (Demerouti } \\
\text { et al. 2001) }\end{array}$ & $\begin{array}{l}\text { Work } \\
\text { Overload }\end{array}$ & $\begin{array}{l}\text { Memiliki banyak pekerjaan } \\
\text { Memiliki pekerjaan dibawah tekanan } \\
\text { Pekerjaan tidak sesuai job desk } \\
\text { Pekerjaan mempengaruhi hal pribadi } \\
\text {. Pekerjaan mempengaruhi emosional }\end{array}$ \\
\hline $\begin{array}{l}\text { Flexible } \\
\text { Leadership } \\
\text { (Kaiser dan }\end{array}$ & Forceful & $\begin{array}{l}\text { Mengambil alih } \\
\text { Deklarasi } \\
\text { Pushes } \\
\end{array}$ \\
\hline
\end{tabular}




\begin{tabular}{lll}
\hline Overfield, & Enabling & . Empowers \\
2010) & . Mendengarkan \\
& . Support \\
\hline
\end{tabular}

\section{HASIL DAN PEMBAHASAN}

Gambaran secara keseluruhan total work engagement dalam memperoleh hasilnya dilakukan pengolahan data menggunakan analisis descriptive statistic. Berdasarkan hasil pengolahan data pada MR di PT X, skala kontinum work engagement minimal adalah 1 dan maksimal adalah 4 . Nilai rata-rata work engagement adalah $\mathrm{M}=3,13$ dan $\mathrm{SD}=0,54$. Nilai rata-rata skor work engagement pada MR di PT X ini cenderung lebih tinggi dibandingkan dengan nilai titik tengah alat ukur yaitu 2,50. Untuk lebih jelas dapat dilihat pada Tabel 2. Dalam work engagement terdapat tiga dimensi, yaitu Vigor, Absorption, dan Dedication. Peneliti akan menjelaskan gambaran masing-masing dimensi.

Tabel 2. Gambaran Total Work Engagement

\begin{tabular}{l|l|l|l|l}
\hline & Min & Max & Mean & Std. Deviation \\
\hline WE & 1.24 & 4.00 & 3.1317 & .54015 \\
\hline
\end{tabular}

Untuk memperoleh hasil gambaran Vigor, dilakukan pengolahan data menggunakan analisis descriptive statistic. Berdasarkan hasil pengolahan data, diperoleh hasil gambaran Vigor pada MR di PT X. Skala kontinum vigor minimal adalah 1 dan maksimal adalah 4. Nilai rata-rata Vigor adalah $\mathrm{M}=3,076$ dan $\mathrm{SD}=0,61$. Nilai rata-rata skor Vigor pada $\mathrm{MR}$ di PT $\mathrm{X}$ ini cenderung lebih tinggi dibandingkan dengan nilai titik tengah alat ukur yaitu 2,50. Artinya, para MR di PT X memiliki skor vigor yang tinggi yang berarti memiliki mental yang kuat selama bekerja, keberanian untuk berusaha sekuat tenaga dalam menyelesaikan suatu pekerjaan, tekun dalam menghadapi kesulitan kerja, dan stamina yang tinggi ketika bekerja. Juga kemauan untuk menginvestasikan segala upaya dalam suatu pekerjaan, dan tetap bertahan meskipun menghadapi kesulitan. Untuk memperoleh hasil gambaran dedication, dilakukan pengolahan data menggunakan analisis descriptive statistic. Berdasarkan hasil pengolahan data, diperoleh hasil gambaran dedication pada MR di PT X. Skala kontinum dedication minimal adalah 1 dan maksimal adalah 4. Nilai rata-rata dedication adalah $\mathrm{M}=3,024$ dan $\mathrm{SD}=0,60$. Nilai rata-rata skor dedication pada MR di PT X ini cenderung lebih tinggi dibandingkan dengan nilai titik tengah alat ukur yaitu 2,50. Artinya, para MR di PT X memiliki skor dedication yang tinggi yang berarti orang-orang yang kuat mengidentifikasi pekerjaan mereka karena menjadikannya pengalaman berharga, menginspirasi dan menantang di dalam pekerjaannya. Untuk memperoleh hasil gambaran Absorption, dilakukan pengolahan data menggunakan analisis descriptive statistic. Berdasarkan hasil pengolahan data, diperoleh hasil gambaran Absorption pada MR di PT X. Skala kontinum Absorption minimal adalah 1 dan maksimal adalah 4. Nilai rata-rata Absorption adalah $\mathrm{M}=3,090$ dan $\mathrm{SD}=0,51$. Nilai rata-rata skor Absorption pada MR di PT X ini cenderung lebih tinggi dibandingkan dengan nilai titik tengah alat ukur yaitu 2,50. Artinya, para MR di PT X memiliki skor Absorption yang tinggi yang berarti orang-orang yang memiliki skor tinggi pada absorption biasanya merasa senang perhatiannya tersita oleh pekerjaan, merasa tenggelam dalam pekerjaan dan memiliki kesulitan untuk memisahkan diri dari pekerjaan. Akibatnya, apapun disekelilingnya terlupakan dan waktu terasa berlalu cepat. Untuk lebih jelas dapat dilihat pada Tabel 3 . 
Tabel 3. Gambaran Komitmen Kerja

\begin{tabular}{lccccc}
\hline Komitmen Kerja & $\mathrm{N}$ & Min & Max & Mean & Std. Deviation \\
\hline Vigor & 46 & 1.17 & 4.00 & 3.0761 & .61132 \\
Dedication & 46 & 1.20 & 4.00 & 3.2478 & .60396 \\
Absorption & 46 & 1.33 & 4.00 & 3.0906 & .51245 \\
\hline
\end{tabular}

Untuk memperoleh hasil gambaran work overload, dilakukan pengolahan data menggunakan analisis descriptive statistic. Berdasarkan hasil pengolahan data, diperoleh hasil gambaran work overload pada MR di PT X. Skala kontinum work overload minimal adalah 1 dan maksimal adalah 4. Nilai rata- rata work overload adalah $\mathrm{M}=2,89$ dan $\mathrm{SD}=0,61$. Nilai rata-rata skor work overload pada MR di PT X ini cenderung lebih tinggi dibandingkan dengan nilai titik tengah alat ukur yaitu 2,50. Artinya, para MR di PT X memiliki skor work overload yang tinggi yang berarti memiliki tuntutan yang tinggi pada pencapaian target dalam sebulan, banyaknya jumlah dokter yang harus ia datangi, beban mental ketika harus berhadapan dengan dokter yang berbeda karakter dan beban emosional ketika di akhir bulan belum mencapai target. Untuk lebih jelas dapat dilihat pada Tabel 4.

Tabel 4. Gambaran Tuntutan Kerja

\begin{tabular}{llll|l|l}
\hline Tuntutan Kerja & $\mathrm{N}$ & Min & Max & Mean & Std. Deviation \\
\hline Work Overload & 46 & 1.75 & 4.00 & 2.8967 & .61084 \\
\hline
\end{tabular}

Gambaran secara keseluruhan total kepemimpinan fleksibel dalam memperoleh hasilnya dilakukan pengolahan data menggunakan analisis descriptive statistic. Berdasarkan hasil pengolahan data pada MR di PT X, skala kontinum kepemimpinan fleksibel minimal adalah 1 dan maksimal adalah 4. Nilai rata-rata kepemimpinan fleksibel adalah $\mathrm{M}=3,03$ dan $\mathrm{SD}=0,48$. Nilai rata-rata skor kepemimpinan fleksibel pada MR di PT X ini cenderung lebih tinggi dibandingkan dengan nilai titik tengah alat ukur yaitu 2,50. Untuk lebih jelas dapat dilihat pada Tabel 5. Dalam kepemimpinan fleksibel terdapat dua dimensi, yaitu Forceful, dan Enabling. Peneliti akan menjelaskan gambaran masing-masing dimensi.

Tabel 5. Gambaran Total Kepemimpinan Fleksibel

\begin{tabular}{l|l|l|l|l} 
& Min & Max & Mean & Std. Deviation \\
\hline Kepemimpinan Fleksibel & 1.71 & 3.93 & 3.0345 & .48766 \\
\hline
\end{tabular}

Forceful Leadership ialah bagaimana pemimpin memimpin dan mendorong kinerja bawahannya dalam mencapai target. Biasanya pemimpin mengambil alih, menentukan, dan bertanggung jawab dalam tugasnya. Dalam Forceful Leadership terdapat tiga indikator yaitu, takes charge, declare, dan pushes. Untuk memperoleh hasil gambaran takes charge, dilakukan pengolahan data menggunakan analisis descriptive statistic. Berdasarkan hasil pengolahan data, diperoleh hasil gambaran takes charge pada AM di PT X. Skala kontinum takes charge minimal adalah 1 dan maksimal adalah 4 . Nilai rata-rata takes charge adalah $\mathrm{M}=2,74$ dan $\mathrm{SD}=0,58$. Nilai rata- 
rata skor takes charge pada AM di PT X ini cenderung lebih tinggi dibandingkan dengan nilai titik tengah alat ukur yaitu 2,50. Artinya, para AM di PT X memiliki skor takes charge yang tinggi yang berarti pemimpin otoriter, yaitu dengan memberikan tugas dalam pencapaian target pada MR, dan menjelaskan tata cara untuk menyelesaikan masalah yang muncul. Untuk memperoleh hasil gambaran declares, dilakukan pengolahan data menggunakan analisis descriptive statistic. Berdasarkan hasil pengolahan data, diperoleh hasil gambaran declares pada AM di PT X. Skala kontinum declares minimal adalah 1 dan maksimal adalah 4. Nilai rata-rata declares adalah $\mathrm{M}=2,99$ dan $\mathrm{SD}=0,65$. Nilai rata-rata skor declares pada $\mathrm{AM}$ di $\mathrm{PT} \mathrm{X}$ ini cenderung lebih tinggi dibandingkan dengan nilai titik tengah alat ukur yaitu 2,50. Artinya, para AM di PT X memiliki skor declares yang tinggi yang berarti AM menentukan semuanya, mengambil posisi yang ia terima, dan mempertahankan jabatannya sebagai AM. Untuk memperoleh hasil gambaran pushes, dilakukan pengolahan data menggunakan analisis descriptive statistic. Berdasarkan hasil pengolahan data, diperoleh hasil gambaran pushes pada AM di PT X. Skala kontinum pushes minimal adalah 1 dan maksimal adalah 4. Nilai rata-rata pushes adalah $\mathrm{M}=3,11$ dan $\mathrm{SD}=0,59$. Nilai rata-rata skor pushes pada AM di PT X ini cenderung lebih tinggi dibandingkan dengan nilai titik tengah alat ukur yaitu 2,50. Artinya, para AM di PT X memiliki skor pushes yang tinggi yang berarti AM memiliki harapan yang tinggi pada MR dan bertanggung jawab penuh pada MR yang menjadi bawahannya. Untuk lebih jelas dapat dilihat pada Tabel 6.

Enabling leadership ialah dimana pemimpin menciptakan kondisi bagi orang lain untuk memimpin dan berkontribusi. Biasanya dalam hal ini pemimpin berusaha untuk memberdayakan bawahannya agar mandiri atau berdiri sendiri tanpa bantuannya, menerima masukan, serta menghargai bawahannya. Dalam enabling leadership terdapat tiga indicator yaitu, empowers, listens, dan support. Untuk memperoleh hasil gambaran empowers, dilakukan pengolahan data menggunakan analisis descriptive statistic. Berdasarkan hasil pengolahan data, diperoleh hasil gambaran empowers pada AM di PT X. Skala kontinum empowers minimal adalah 1 dan maksimal adalah 4. Nilai rata-rata empowers adalah $\mathrm{M}=3,01$ dan $\mathrm{SD}=0,47$. Nilai rata-rata skor empowers pada AM di PT X ini cenderung lebih tinggi dibandingkan dengan nilai titik tengah alat ukur yaitu 2,50. Artinya, para AM di PT X memiliki skor empowers yang tinggi yang berarti AM memberi ruang atau kesempatan bagi MR dalam memecahkan masalah, dan mempercayakan MR dalam memecahkan masalah. Untuk memperoleh hasil gambaran listens, dilakukan pengolahan data menggunakan analisis descriptive statistic. Berdasarkan hasil pengolahan data, diperoleh hasil gambaran listens pada AM di PT X. Skala kontinum listens minimal adalah 1 dan maksimal adalah 4. Nilai rata-rata listens adalah $\mathrm{M}=3,03$ dan $\mathrm{SD}=0,61$. Nilai rata-rata skor listens pada AM di PT X ini cenderung lebih tinggi dibandingkan dengan nilai titik tengah alat ukur yaitu 2,50. Artinya, para AM di PT X memiliki skor listens yang tinggi yang berarti AM berpartisipatif dalam mengerjakan tugas, mempertimbangkan masukan dari MR, dan berpikir terbuka dalam menangani masalah bersama-sama. Untuk memperoleh hasil gambaran support, dilakukan pengolahan data menggunakan analisis descriptive statistic. Berdasarkan hasil pengolahan data, diperoleh hasil gambaran support pada AM di PT X. Skala kontinum support minimal adalah 1 dan maksimal adalah 4 . Nilai rata-rata support adalah $\mathrm{M}=$ 3,04 dan SD =0,50. Nilai rata-rata skor support pada AM di PT X ini cenderung lebih tinggi dibandingkan dengan nilai titik tengah alat ukur yaitu 2,50. Artinya, para AM di PT X memiliki skor support yang tinggi yang berarti AM memperlakukan MR dengan baik, menunjukkan akan saling menghargai, dan memberikan MR manfaat dari mendapatkan masalah. Untuk lebih jelas dapat dilihat pada Tabel 6 . 
Tabel 6. Gambaran Kepemimpinan Fleksibel

\begin{tabular}{l|ll|l|l|l|l}
\hline \multicolumn{1}{l}{ Kepemimpinan Fleksibel } & $\mathrm{N}$ & Min & Max & Mean & Std. Deviation \\
\hline \multirow{2}{*}{ Forceful } & Takes Charge & 46 & 1.50 & 4.00 & 2.7391 & .58915 \\
\cline { 2 - 7 } & Empowers & 46 & 2.00 & 4.00 & 3.0163 & .46964 \\
\cline { 2 - 7 } & Declares & 46 & 1.00 & 4.00 & 2.9946 & .65083 \\
\hline \multirow{3}{*}{ Enabling } & Listens & 46 & 1.25 & 4.00 & 3.0272 & .61289 \\
\cline { 2 - 7 } & Pushes & 46 & 1.75 & 4.00 & 3.1141 & .59326 \\
\cline { 2 - 7 } & Support & 46 & 2.00 & 4.00 & 3.0435 & .50361 \\
\hline
\end{tabular}

Berdasarkan hasil uji normalitas, sebaran data pada vigor dan forceful adalah normal (Statistik Parametrik). Oleh karena itu uji korelasi pearson digunakan untuk menguji hubungan antara dimensi flexible leadership dan vigor dalam bentuk analisis korelasi dengan menggunakan aplikasi SPSS versi 25 One-Sample Kolmogorov-Smirnov Test.

Tabel 7. Uji Normalitas One-Sample Kolmogorov-Smirnov Test One-Sample Kolmogorov-Smirnov Test

\begin{tabular}{lll|l|l} 
& \multicolumn{2}{c}{ FL } & WE & JD \\
\hline $\mathrm{N}$ & & 46 & 46 & 46 \\
\hline Normal Parameters & & & \\
& Mean & 3.0345 & 3.1317 & 3.1936 \\
\cline { 2 - 5 } & Std. Deviation & .48766 & .54015 & .41491 \\
\hline Asymp. Sig. (2-tailed) & & $.200^{\mathrm{c}, \mathrm{d}}$ & $.200^{\mathrm{c}, \mathrm{d}}$ & $.200^{\mathrm{c}, \mathrm{d}}$ \\
\hline
\end{tabular}

Berdasarkan hasil uji normalitas, sebaran data pada work engagement dan job demands adalah normal (Statistik Parametrik). Oleh karena itu uji korelasi pearson digunakan untuk menguji hubungan antara dimensi work engagement dan work overload dalam bentuk analisis korelasi dengan menggunakan aplikasi SPSS versi 25. Pada variabel job demands memiliki 1 dimensi, yaitu work overload, dan work engagement memiliki 3 dimensi yaitu, vigor, dedication, dan absorption.

Dimensi yang memiliki hubungan positif dan signifikan dengan work overload yaitu, pada work engagement terdapat dimensi pertama vigor $\left(\mathrm{r}_{\mathrm{S}}=0,282, \mathrm{p} 0,058>0,05\right)$, dimensi kedua dedication $\left(\mathrm{r}_{\mathrm{S}}=0,342, \mathrm{p} 0,020>0,05\right)$, dan dimensi ketiga absorption $\left(\mathrm{r}_{\mathrm{S}}=0,341, \mathrm{p} 0,020>\right.$ 0,05). Dapat disimpulkan bahwa semakin memiliki banyak pekerjaan, banyak deadline, pekerjaan tidak sesuai job desk, dan pekerjaan mempengaruhi diri MR, maka MR semakin semangat bekerja, merasa bekerja adalah hal menyenangkan, antusias dalam bekerja, dan menyadari bahwa pekerjaannya penuh dengan tantangan. 
Tabel 8. Hasil Uji Korelasi Dimensi Work Engagement dengan prediktor Job Demands

\begin{tabular}{lcc}
\hline \multirow{2}{*}{ Work Engagement } & \multicolumn{3}{c}{ Job Demands } \\
\cline { 2 - 3 } & $\mathrm{r}$ & Sig. \\
\hline Vigor & 0,282 & 0,058 \\
Dedication & 0,342 & 0,020 \\
Absorption & 0,341 & 0,020 \\
\hline
\end{tabular}

Catatan. ${ }^{*} \mathrm{p}<0,05 . * * \mathrm{p}<0,01$.

Berdasarkan hasil uji normalitas, sebaran data pada Work Engagement, Flexible Leadership sebagai moderator, dan Job Demands adalah normal (Statistik Parametrik). Oleh karena itu uji korelasi pearson digunakan untuk menguji hubungan dalam bentuk analisis korelasi dengan menggunakan aplikasi SPSS versi 25.

Pada uji korelasi yang pertama ialah melihat korelasi antara work engagement, job demands dengan flexible leadership sebagai moderator. Pada korelasi keseluruhan dimensi antara work engagement dengan flexible leadership memiliki hubungan yang rendah dan tidak signifikan pada work engagement $\left(r_{\mathrm{S}}=0,075, \mathrm{p} 0,622>0,05\right)$ dan pada job demands $\left(\mathrm{r}_{\mathrm{S}}=-0,143, \mathrm{p} 0,344>\right.$ 0,05). Dapat disimpulkan bahwa ketika ada atau tidak adanya pemimpin bersikap otoriter dan memberdayakan MR. Maka rendahnya hubungan flexible leadership sebagai moderator dengan work engagement dan job demands, yang artinya MR akan semangat, tekun dan antusias dalam bekerja, memiliki banyak tugas kerja, deadline, dan pekerjaan memengaruhi hal pribadi, tanpa harus memiliki pemimpin yang memiliki gaya kepemimpinan yang fleksibel.

Pada uji korelasi yang pertama ialah melihat korelasi antara work engagement, job demands dengan flexible leadership sebagai moderator. Pada korelasi keseluruhan dimensi antara work engagement dan job demands dengan flexible leadership sebagai moderator memiliki hubungan yang tinggi dan signifikan pada work engagement $\left(r_{S}=0,339, p 0,021<0,05\right)$. Dapat disimpulkan bahwa ketika pemimpin bersikap mendorong dan memberdayakan MR, flexible leadership sebagai moderator memperkuat hubungan work engagement dan job demands, yang artinya MR akan semangat, tekun dan antusias dalam bekerja, memiliki banyak tugas kerja, deadline, dan pekerjaan memengaruhi hal pribadi, dengan memiliki pemimpin yang memiliki gaya kepemimpinan yang fleksibel.

Tabel 9. Hasil Uji Korelasi Work Engagement, Job Demands, dan Dimensi Flexible Leadership

\begin{tabular}{lcccc}
\hline & \multicolumn{2}{c}{ Work Engagement } & \multicolumn{2}{c}{ Job Demands } \\
\cline { 2 - 5 } Dimensi Flexible Leadership & $\mathrm{r}$ & Sig. & $\mathrm{r}$ & Sig. \\
Forceful & 0,339 & 0,021 & 0,339 & 0,021 \\
Enabling & 0,339 & 0,021 & 0,339 & 0,021 \\
Catatan. ${ }^{*} \mathrm{p}<0,05 . * \mathrm{p}<0,01$. & & & &
\end{tabular}

Pada uji korelasi yang kedua ialah melihat korelasi antara work engagement, dan job demands, dengan flexible leadership yang rendah sebagai moderator. Pada korelasi keseluruhan dimensi antara work engagement dan job demands dengan flexible leadership sebagai prediktor tidak memiliki hubungan dan tidak signifikan pada work engagement dan job demands $\left(\mathrm{r}_{\mathrm{S}}=0,380, \mathrm{p}\right.$ 
$0,354>0,05)$. Dapat disimpulkan bahwa ketika rendahnya pemimpin bersikap otoriter dan memberdayakan MR, maka lemahnya hubungan work engagement dan job demands, yang artinya ketika MR mendapatkan tuntutan kerja maka rendahnya semangat kerja pada MR, malas dalam bekerja, dan tidak tertarik dalam bekerja, jika memiliki pemimpin dengan gaya kepemimpinan fleksibel yang rendah.

Tabel 10. Hasil Uji Korelasi Work Engagement, Job Demands, dan Flexible Leadership

\begin{tabular}{lccc}
\hline \multicolumn{4}{c}{ Rendah } \\
\cline { 2 - 4 } & $\mathrm{N}$ & $\mathrm{r}$ & Slexible Leadership Rendah \\
\hline Work Engagement & 8 & 0,380 & 0,354 \\
Job Demands & 8 & 0,380 & 0,354 \\
\hline
\end{tabular}

Catatan. $* \mathrm{p}<0,05 . * * \mathrm{p}<0,01$.

Pada uji korelasi yang ketiga ialah melihat korelasi antara work engagement, dan job demands dengan flexible leadership yang tinggi sebagai moderator. Pada korelasi keseluruhan dimensi antara work engagement, dan job demands, dengan flexible leadership yang tinggi sebagai moderator memiliki hubungan positif dan signifikan $\left(\mathrm{r}_{\mathrm{S}}=0,333, \mathrm{p} 0,041<0,05\right)$. Dapat disimpulkan bahwa ketika MR mendapatkan tuntutan kerja dan memiliki pemimpin dengan gaya kepemimpinan yang mendorong dan memberdayakan kinerja MR, maka MR akan semangat kerja, tekun dalam bekerja, dan antusias dalam bekerja.

Tabel 11. Hasil Uji Korelasi Work Engagement, Job Demands, dan Flexible Leadership Tinggi

\begin{tabular}{lccc}
\hline & \multicolumn{3}{c}{ Flexible Leadership Rendah } \\
\cline { 2 - 4 } & $\mathrm{N}$ & $\mathrm{r}$ & Sig. \\
\hline Work Engagement & 38 & 0,333 & 0,041 \\
Job Demands & 38 & 0,333 & 0,041 \\
\hline
\end{tabular}

Catatan. *p $<0,05 . * * p<0,01$.

\section{Diskusi}

Dalam penelitian ini dapat dijelaskan bahwa adanya peranan negative variabel flexible leadership pada job demands dan work engagement. Penemuan ini tidak sejalan dengan Breevaart \& Bakker (2017) yang menjelaskan bahwa perilaku kepemimpinan mendukung work engagement karyawan yang dicirikan oleh job demands yang tinggi, dan melindungi work engagement yang dicirikan oleh job demands tinggi. Maka semakin tingginya work engagement maka akan semakin tinggi pula job demands dengan di mediator oleh flexible leadership. Pertimbangan dalam kelemahan peneliti ini ialah dari jumlah partisipan sendiri yang kurang dari 60 karyawan, karena terbatas. Kelemahan lainnya ialah dari masalah waktu, peneliti berusaha semaksimal mungkin untuk menjelaskan pada partisipan mengenai penelitian ini, namun kurang diperdulikan. Penelitian sebelumnya lebih melihat keseharian partisipan, jika peneliti hanya melihat secara observasi dan wawancara, sementara pengetesan hanya sekali.

\section{KESIMPULAN DAN SARAN}

Kesimpulan dari keseluruhan penelitian ini menganalisis hubungan antara job demands dengan work engagement, dapat disimpulkan keduanya memiliki hubungan yang kuat. Hubungan antara job demands sebagai prediktor dengan work engagement semakin kuat dengan adanya flexible 
leadership sebagai moderator. Hubungan antara job demands sebagai prediktor dengan work engagement, semakin rendah dengan dimoderatori oleh flexible leadership yang rendah. Hubungan antara job demands sebagai prediktor dengan work engagement, semakin berhubungan ketika dimoderatori oleh flexible leadership yang tinggi. Jadi dapat disimpulkan bahwa dengan adanya flexible leadership sebagai moderator, maka hubungan job demands sebagai prediktor dengan work engagement semakin kuat pada MR di PT X Kab. Bogor.

Saran dalam penelitian ini, mengenai penelitian selanjutnya agar dapat ditelusuri lebih lanjut mengenai job demands dan work engagement pada MR, karena banyak aspek tertentu yang dapat dilihat selain dari flexible leadership yaitu, motivasi kerja dan turnover. Penelitian selanjutnya juga di usahakan untuk lebih banyak partisipan agar tidak terjadi kesulitan ketika menjalani proses dalam aplikasi pengambilan data. Mengenai saran praktis yang diberikan oleh peneliti ditujukan bagi kedua belah pihak yaitu, untuk MR dan AM. Berdasarkan hasil penelitian, MR dapat bekerja lebih baik ketika adanya keterikatan kerja, walaupun tuntutan pekerjaan menghampiri pekerjaan MR, namun MR akan lebih merasa terikat dengan perusahaan. Buatlah MR senyaman mungkin dengan diadakannya sharing antar MR dan AM. Berdasarkan penelitian, AM dapat menjadi pemimpin yang fleksibel, karena dapat berpengaruh untuk menguatkan MR dalam bekerja. Demi kenyamanan bersama, tentu pencapaian target akan terlaksana dengan baik jika tidak adanya keraguan antara MR dengan AM, karena keduanya memiliki tujuan yang sama yaitu, sama-sama ingin mencapai target yang telah di tentukan oleh perusahaan.

\section{REFERENSI}

Bakker, A. B., \& Demerouti, E. (2014). Job demands-resources theory. In C. Cooper \& P. Chen (Eds.), Wellbeing: A complete reference guide (pp. 37-64). Chichester, UK: WileyBlackwell. http://dx.doi.org/10.1002/ 9781118539415.wbwell019

Bakker, A. B., Demerouti, E., Taris, T. W., Schaufeli, W. B., \& Schreurs, P. J. G. (2003). A multigroup analysis of the job demands-resources model in four home care organizations. International Journal of Stress Management, 10(1), 16-38. http://dx.doi.org/10.1037/1072-5245.10.1.16

Bakker, A. B., Demerouti, E. \& Schaufeli, W. B. (2003). Dual processes at work in a call centre: An application of the job demands-resources model. European Journal of Work and Organizational Psychology, 12, 393-417.

Breevaart, K., Bakker, A. B. (2017). Daily job demands and employee work engagement: The role of daily transformational leadership behavior. Journal of Occupational Health Psychology. Advance online publication.

Kaiser, R. B., Hogan, R., \& Craig, S. B. (2008). Leadership and the fate of organizations. American Psychologist, 63, 96-110.

Kaiser, R. B., Lindberg, J. T., \& Craig, S. B. (2007). Assessing the flexibility of managers: A comparison of methods. International Journal of Selection and Assessment, 16, 40-55.

Kaiser, R. B., Overfield, D. V., \& Kaplan, R. E. (2010). Leadership versatility index version 3.0: Facilitator's guide. Greensboro, NC: Kaplan DeVries Inc.

Kaiser, R. B., \& Overfield, D. V. (2010). Assessing flexible leadership as a mastery of opposites. Consulting Psychology Journal: Practice and Research, 62(2), 105-118.

Rothmann, et al. (2006). A psychometric evaluation of the job demands-resources scale in south africa. SA Journal of Industrial Psychology, 32(4), 76-86.

Schaufeli, W. B. \& Bakker, A. B. (2004). Job demands, job resources, and their relationship with burnout and engagement: A multi-sample study. Journal of Organizational Behavior, 25, $1-23$.

Schaufeli, W., \& Bakker A. (2004). Work Engagement Scale. 